(236)

\title{
Potential of Making Fungal Toxins at Commercial Scale for Agarwood Inducement
}

\author{
Malithi R.A.P. ${ }^{1 *}$, Subasinghe S.M.C.U.P. ${ }^{1}$, Fernando T.H.P.S ${ }^{2}$ \\ ${ }^{1}$ Department of Forestry \& Environmental Science, University of Sri Jayewardenepura, Sri Lanka \\ ${ }^{2}$ Plant Pathology \& Microbiology Department, Rubber Research Institute, Sri Lanka \\ *21pramodyaranasinghe@gmail.com
}

\begin{abstract}
Agarwood, a highly valuable resin formed in the stems and roots of certain tree species of the family Thymlaeaceae can be induced the formation in artificial manner by using different fungal species. The potential of fungal toxins using certain strains of Aspergillus niger and Fusarium solani to form agarwood in Gyrinops walla, which is a native species to Sri Lanka, was identified in 2016. However, the potential of extracting fungal toxins in large scale was not studied previously for the purpose of inducing agarwood formation at commercial scale. Therefore selected strains of $A$. niger and $F$. solani were grown on Potato Dextrose Agar (PDA) medium and three agar plugs of $A$. niger were inoculated in Czapek Dox Broth (CDB) and $F$. solani in Yeast Extract Glucose Broth (YEGB). A 50, 100, 150, 200, 250, 300 and 500 $\mathrm{ml}$ series was prepared for CDB and YEGB to identify the potential impacts of different volumes of toxins. Mycotoxins were extracted after 14 days for A. niger and after 10 days for $F$. solani based on the results of a previous study. The impacts of those toxins were detected by a bioassay using A. crassna and G. walla leaves. A comparison was made using diameters of lesions caused by toxins in A. crassna and G. walla leaves after 48 hour. According to the results, the effects of toxins of $F$. solani and $A$. niger were not significant on $A$. crassna. Further the damage caused by $F$. solani $(\mathrm{F}=1.02 ; \mathrm{P}=0.428)$ and $A$. niger $(\mathrm{F}=1.41 ; \mathrm{P}=0.238)$ grown in different volumes was not statistically significant. However, the effect of toxins of $F$. solani was significantly higher than that of $A$. niger $(\mathrm{F}=10.69 ; \mathrm{P}=0.000)$ on G. walla. Damage caused by toxins formed in different volumes of $F$. solani was not significant $(\mathrm{F}=1.81 ; \mathrm{P}=0.103)$ on the leaves of both species. However, the damages caused by toxins $A$. niger grown in $50 \mathrm{ml}$ and $100 \mathrm{ml}$ were significantly lower on $G$. walla leaves than the rest of volumes. Based on these results, $500 \mathrm{ml}$ can be used as an effective volume to extract toxins from $A$. niger and $F$. solani for inducing agarwood formation at commercial scale.
\end{abstract}

Keywords: Fusarium solani, Aspergillus niger, Agarwood resins, Mycotoxins

Acknowledgement: Centre for Forestry and Environment of University of Sri Jayewardenepura and Sadaharitha Plantations Ltd, Colombo 03, Sri Lanka. 